\title{
Comparison on Mechanics Performance of Concrete Column Frame Structure with Prefabricated Cage System
}

\author{
Kewei DING \\ School of Civil Engineering \\ Key Laboratory of Building Structure and Underground \\ Engineering of Anhui Province \\ Anhui Jianzhu University \\ Hefei, China \\ e-mail:dingkw@ahjzu.edu.cn
}

\author{
Weijie ZHANG \\ School of Civil Engineering \\ Key Laboratory of Building Structure and Underground \\ Engineering of Anhui Province \\ Anhui Jianzhu University \\ Hefei, China \\ e-mail: 314236131@qq.com
}

\begin{abstract}
According to the requirements of the project in this paper, the frame structure with reinforced concrete columns and prefabricated cage system concrete columns are designed. Then the Pushover finite element simulation analysis is carried out under the action of one-way increasing load. After that, the axial force, the bending moment, the displacement and the inter-story drift of $\mathrm{RC}$ columns and prefabricated cage system concrete columns are analyzed and compared. Research shows that: under the condition of the same material and the same strength, the mechanics performance of the prefabricated cage system is better than that of the traditional reinforced concrete column. The deformation capacity of the prefabricated cage system concrete columns is slightly higher than that one. Therefore, the mechanics performance of prefabricated cage system is better, and the ductility requirements are fulfilled.
\end{abstract}

Keywords-reinforced concrete column; prefabricated cage system; reinforcing concrete column; mechanics performance; pushover analysis

\section{INTRODUCTION}

Energy methods, strength methods and deformation methods are used to evaluate the performance of components or structures at present. In the evaluation of many structural performance methods, the deformation method is one of the most intuitive, simple and practical. Due to the nonlinear nature of the structure which has considered, this method can reflect the performance level of the structure well. Therefore, the performance evaluation method is the most widely used in code for seismic design of buildings. The building structure such as the bridge and reinforced concrete frame structure, reinforced concrete columns (RC) are selected for main bearing members [1].

The concrete structure of prefabricated cage system [2] (PCS) is a new type of composite frame structure which was jointly tried by Mohanmmad Shamsai and Halil Sezen in 2005[3]. Steel reinforced was replaced by the prefabricated cage system. The steel plate of vertical and horizontal were combined with the connection as one unit. Compared with reinforced concrete, the steel plate size of the PCS is relatively accurate. Compared with concrete filled steel tube (CFST), it is more economical to save the cost of steel. For PCS, the longitudinal plate is used to bear the axial bearing capacity; the lateral is used for limiting the core concrete. In order to achieve the design requirements of the structure, the PCS is through the opening spacing, the size of the holes, and the thickness of the steel plate to control the ratio of steel bars to adjust the parameters [4]. After opening the steel cage, there are horizontal and vertical distinction, horizontal slab equivalent stirrup, and vertical slab equivalent longitudinal reinforcement. The longitudinal reinforcement and stirrup as a whole, in the same piece of steel or steel, so PCS is different from the steel cage. In addition, the PCS can be widely used in different structures such as beams, plates, columns, walls, foundations, etc.. The PCS can be used in combination with other components, and can also be used to form the whole building structure.

\section{SPECIMEN DESIGN}

In this paper, this specimen is designed according to the relevant regulations of China's "Code for Seismic Design of Buildings" (GB50011-2010) [5] and the "Concrete Structure Design Code" (GB50010-2010) [6]. A total of two groups were tested. One is prefabricated cage system reinforcing concrete column frame structure, and the other is reinforced concrete column. Under the same conditions, the results of the finite element analysis software are analyzed and the design of the steel cage concrete column is improved by comparing the differences in seismic performance between different groups.

The prototype used in the test is based on 7 degree $(0.1 \mathrm{~g})$ fortification category according to the "Code for Seismic Design of Buildings" (CB50011-2010) in China. The seismic rating is three grades which structure used in the simulation analysis. A six-story, two-span concrete column frame structure with prefabricated cage system was designed. The concrete parameters are: the height of $3.0 \mathrm{~m}$, the span of $4.0 \mathrm{~m}$, and the column section size of $400 \mathrm{~mm} \times 400 \mathrm{~mm}$, the beam section size of $250 \mathrm{~mm} \times 500 \mathrm{~mm}$, the floor thickness of $120 \mathrm{~mm}$. Those use cast-in-place concrete material. The concrete strength grade of the structure is C30; the longitudinal reinforcement is $\mathrm{HRB} 400$; the stirrup is HPB300; the steel plate is Q235. The structural model diagram is shown in Fig.1. 


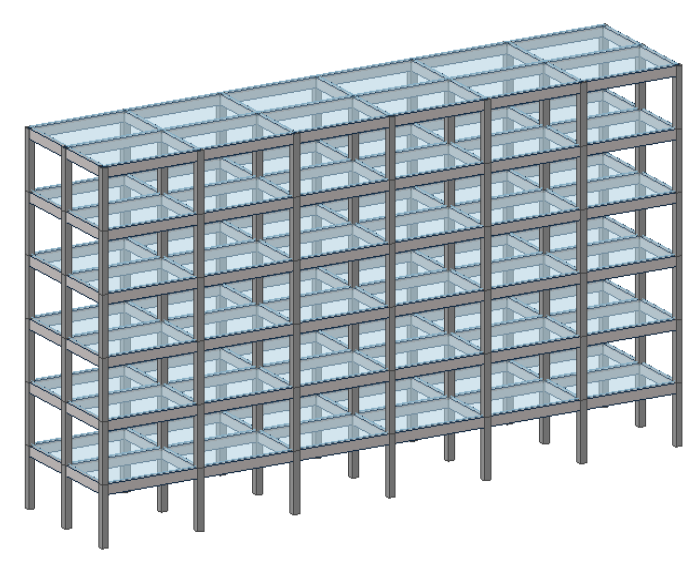

Figure 1. Structural model diagram

\section{NONLINEAR STATIC ANALYSIS}

\section{A. Principle of Software Analysis}

In this paper, the pushover finite element analysis is carried out using the static elastic plastic platform in the software Midas/Building [7].

Pushover analysis is based on the seismic design of the performance. According to the specific needs of the building structure, it set the target performance, and the design of the structure meet the performance of the method. After general design, the structure can meet the requirements of seismic code that undamaged under minor earthquake and repairable under moderate earthquake. Then according to the Pushover analysis, whether the structure can meet the performance index of the preset in big earthquake was investigated [8].

The principle of Pushover analysis is that the intersection point of acceleration displacement demand spectrum which obtained from the large seismic response spectrum and acceleration displacement capacity spectrum of the single degree of freedom system by gradually increasing load to achieve the predetermined displacement, then converted from load displacement capacity curve. It is the performance point [9]. And the performance of the structure is evaluated under the condition of large earthquake by contrasting the value of the displacement between location of the obtained performance point and allowable value of the code [10].

\section{B. Parameter Setting of Pushover Analysis}

The incremental control method is based on displacement control. The initial incremental load $(1 \times \mathrm{DL}$ (dead load) + $0.5 \times \mathrm{LL}$ (live load)) is the initial state of the static elasticplastic analysis of this calculation. The termination analysis condition takes the $1 / 100$ of the top level displacement of the structure which is $180 \mathrm{~mm}$ as target displacement.

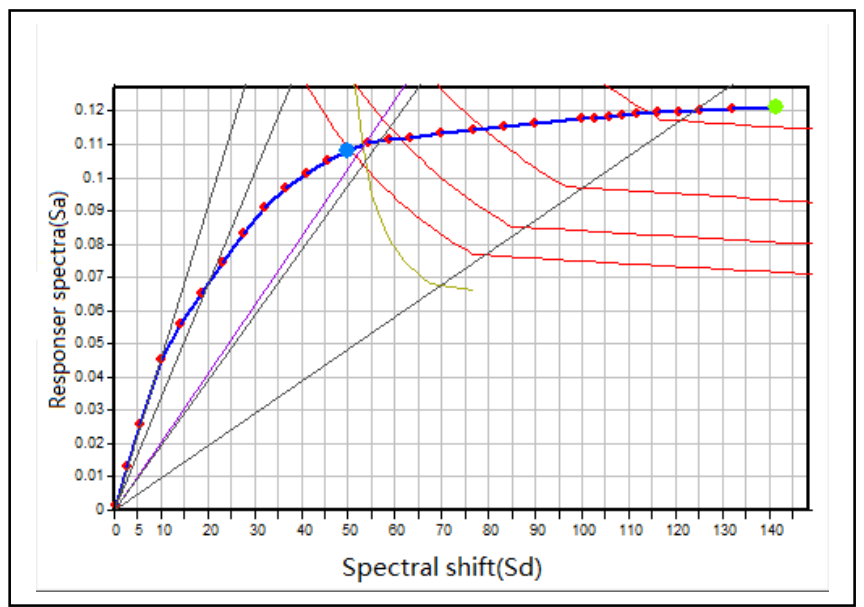

Figure 2. The static elastic-plastic curve of reinforced concrete column frame

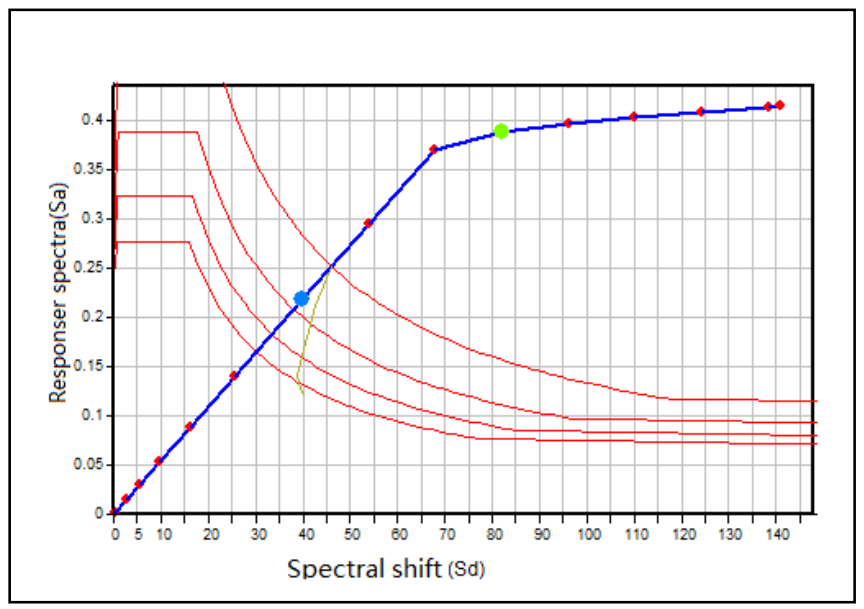

Figure 3. The static elastic-plastic curve of prefabricated cage system reinforcing concrete column frame

\section{Simulation ANALYSIS AND RESUlts}

\section{A. Result of Pushover Performance Point}

Through the finite element software of Midas Building modeling, Pushover analysis is carried out to check and analyze the anti collapse by comparing the two different types of column frame in the fortification intensity of 7 degrees under the rare earthquake.

For the RC column frame structure, the pushover is overturned in 30 steps, and the performance point is found in step 13, as shown in Fig.2. For the PCS column frame structure, it is overturned in 14 steps, and the performance point is found in step 7, as shown in Fig.3. In the Pushover diagram, the results of the performance point are obtained, such as maximum inter-story drift, base shear, maximum displacement and effective damping ratio. 


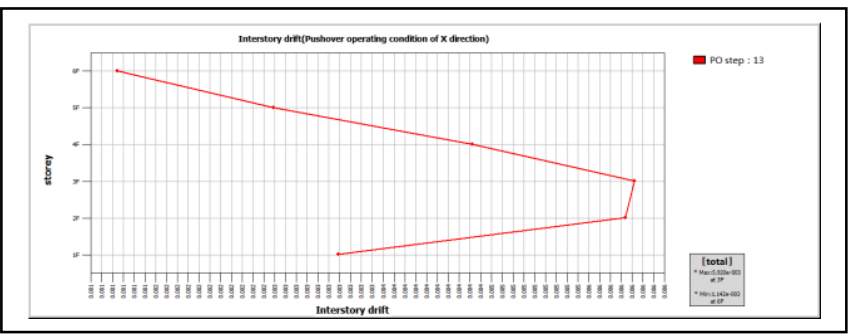

Figure 4. Inter-story drift of reinforced concrete column frame (performance point)

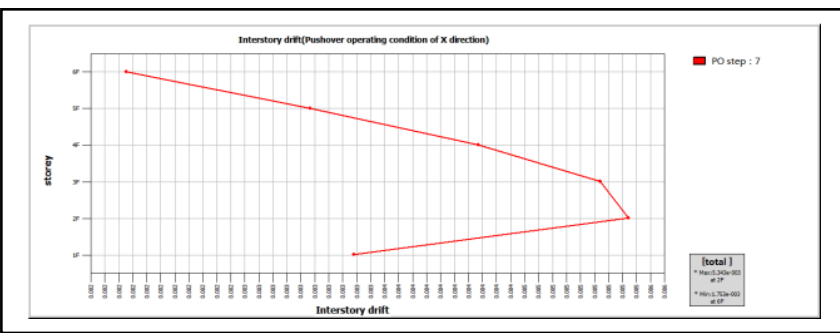

Figure 5. Inter-story drift of prefabricated cage system reinforcing concrete column frame (performance point)

\section{B. Analysis of Inter-story Drift}

From the analysis, the maximum inter-story drift of RC column frame is 0.0059 at the performance point, which occurs in the third layer, as shown in Fig.4, and the maximum of the PCS column frame is 0.0053 , occurred in the second layer, as shown in Fig.5. It means that the stiffness performance of the PCS is superior than the RC column frame. It can be concluded that the inter-story drift of the whole structure is smaller than 1/100 of the elastic-plastic inter-story drift limit specified in the seismic code of China [11]. Above all, the inter-story drift of two kinds of structure is up to specification requirements [12].

\section{Comparative Analysis of Displacement and Axial Force}

For the two groups, the corner column, middle column and side column are selected at the same position for first floor. Under the static elastic-plastic load condition, the maximum deformation and internal force of the column hinge are shown in Table I .

It shows the comparison for the displacement, the bending moment and axial force at the performance point between the frame of the RC column and the PCS column from Fig.6 to Fig.11.

TABLE I. DEFORMATION AND INTERNAL ForCE OF COLUMN HiNGE

\begin{tabular}{|l|c|c|c|c|}
\hline \multirow{2}{*}{ Component } & \multicolumn{2}{|c|}{ Deformation } & \multicolumn{2}{c|}{ Internal Force } \\
\cline { 2 - 5 } & $\boldsymbol{R C}$ & $\boldsymbol{P C S}$ & $\boldsymbol{R C}$ & $\boldsymbol{P C S}$ \\
\hline corner column & $1.167 \times 10^{-2}$ & $3.180 \times 10^{-3}$ & 157.458 & 660.429 \\
\hline middle column & $1.159 \times 10^{-2}$ & $3.504 \times 10^{-3}$ & 235.959 & 727.576 \\
\hline side column & $1.162 \times 10^{-2}$ & $3.515 \times 10^{-3}$ & 209.639 & 729.923 \\
\hline
\end{tabular}

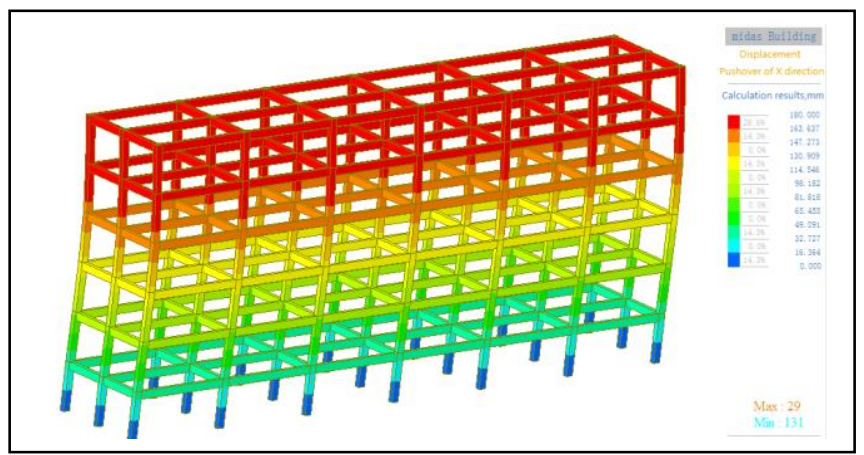

Figure 6. Displacement of reinforced concrete column frame

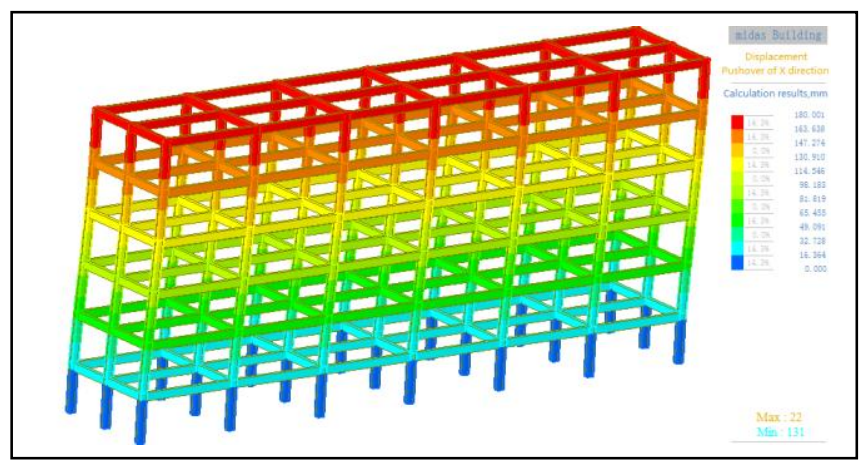

Figure 7. Displacement of prefabricated cage system

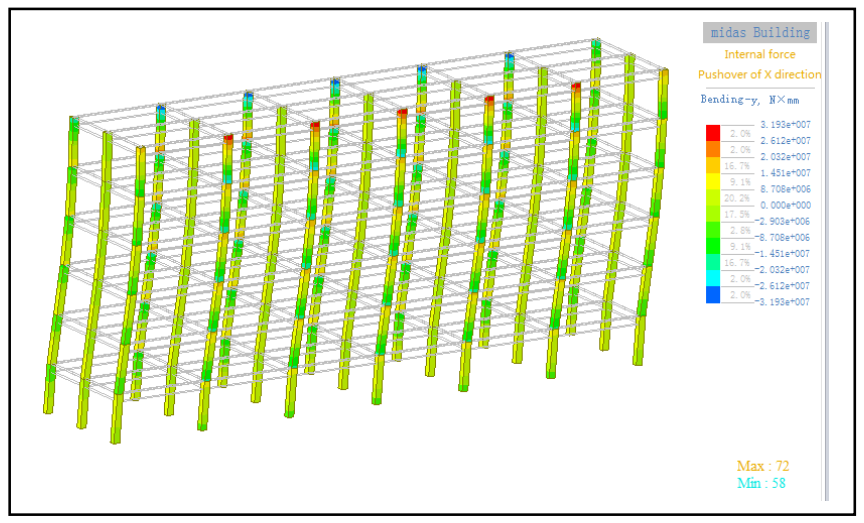

Figure 8. Bending moment of reinforced concrete at performance point

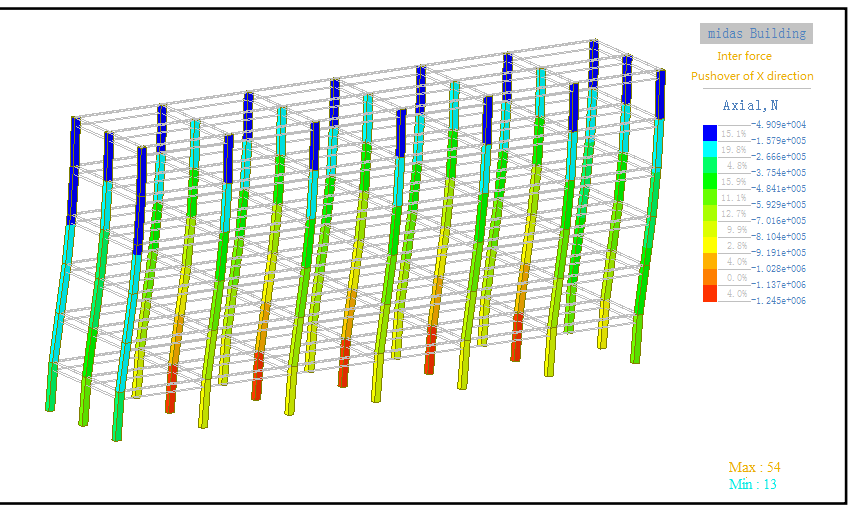

Figure 9. Axial force of reinforced concrete at performance point 


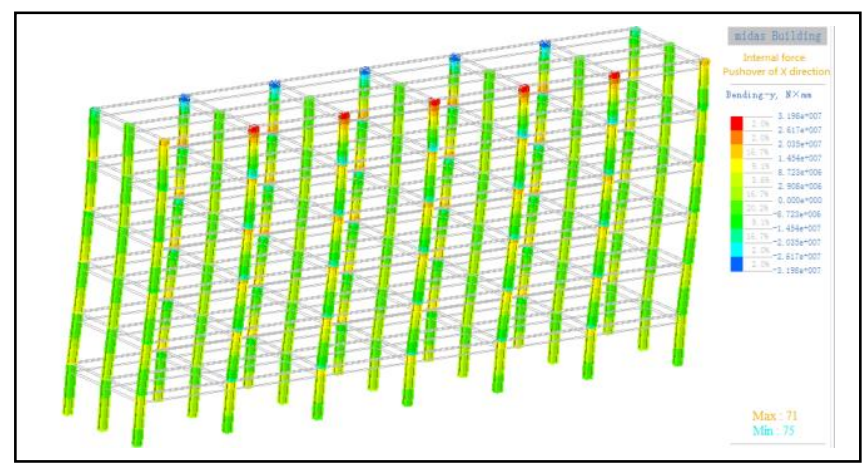

Figure 10. Bending moment of prefabricated cage system at performance point

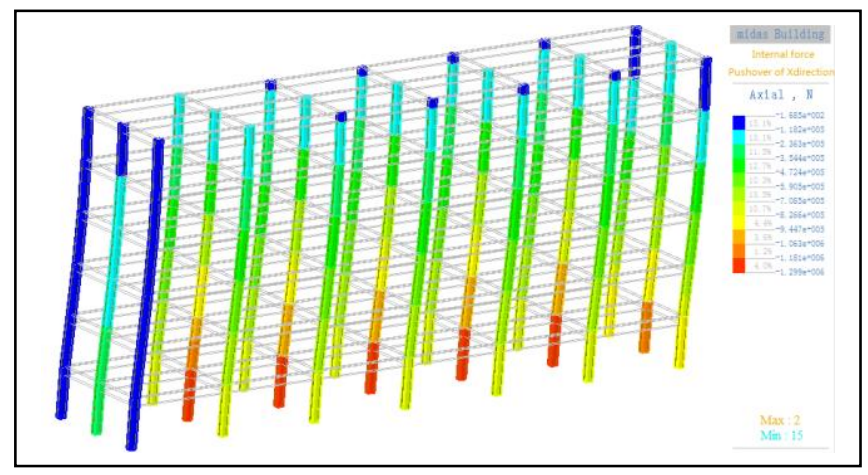

Figure 11. Axial force of prefabricated cage system at performance point

\section{Bearing Capacity and Deformation Capacity}

The bearing capacity is one of the important indexes to measure the seismic performance of components or structures [13]. In Table II, the bearing capacity and the maximum displacement are extract at the starting step, performance point step and end step from the analysis result. According to the Table II, the bearing capacity of RC column is smaller than the PCS column with the increase of horizontal displacement. And the maximum load capacity of the PCS column is 1.12 times of the RC column. The data indicate that the bearing capacity of the PCS is better than that of the RC column, under the same material and strength value. The bearing capacity of PCS column is superior to the RC column about $12 \%$. From the Table II, the deformation displacement of the PCS column at the performance point is $68.85 \mathrm{~mm}$, but the RC column is $59.30 \mathrm{~mm}$, the PCS column is about 1.16 times of it. So, the deformation capacity of the PCS column is better than that.

TABLE II. DEFORMATION AND INTERNAL ForCE OF COLUMN HINGE

\begin{tabular}{|c|c|c|c|c|c|c|}
\hline \multirow{3}{*}{ Component } & \multicolumn{2}{|c|}{ Starting Step } & \multicolumn{2}{c|}{ Performance Point Step } & \multicolumn{2}{c|}{ End Step } \\
\cline { 2 - 7 } & $\begin{array}{c}\text { Displacement } \\
(\boldsymbol{m m})\end{array}$ & $\begin{array}{c}\text { Load } \\
(\boldsymbol{K} \boldsymbol{N})\end{array}$ & $\begin{array}{c}\text { Displacement } \\
(\boldsymbol{m m})\end{array}$ & $\begin{array}{c}\text { Load } \\
(\boldsymbol{K} \boldsymbol{N})\end{array}$ & $\begin{array}{c}\text { Displacement } \\
(\boldsymbol{m m})\end{array}$ & $\begin{array}{c}\text { Load } \\
(\boldsymbol{K} \boldsymbol{N})\end{array}$ \\
\hline $\mathrm{RC}$ & 3.60 & 1248 & 59.30 & 1245 & 180.00 & 1248 \\
\hline PCS & 3.60 & 1372 & 68.85 & 1399 & 180.00 & 1411 \\
\hline
\end{tabular}

\section{CONCLUSION}

In this paper, the results of Midas Building software are processed and analyzed. The following conclusions are drawn:

- Under the same conditions, the maximum capacity of the PCS column is 1.12 times of the RC column. So the performance of the PCS column is better than the RC, and the PCS bear greater load show that have greater bearing capacity.

- Under the same load level, the deformation of the PCS is smaller than that of the traditional RC column. Comparing the ultimate load of each column, the stiffness of the PCS which is reflected more superior in the mechanical properties is stronger and the integrity of the one is better.

- Through the analysis, the PCS has the possibility to replace the RC column in the design and application side.

\section{ACKNOWLEDGMENT}

This project supported by Anhui Provincial Science and Technology Research Project Funding through grant No.1501041133, and Anhui Provincial Universities Natural Science Research Project No. KJ2015A046.

\section{REFERENCES}

[1] LI Ji, LIU Rushan and YUE Xiao, "Study on deformation performance of flexural damage in reinforced concrete columns," Earthquake Engineering and Engineering Dynamics, Apr. 2014, pp. 212-218.

[2] Mohammad Shamsai, Prefabricated Cage System for Reinforcing Concrete Members. Columbus: The Ohio State University, 2006.

[3] Halil Sezen and Mohammad Shamsai, "High-Strength concrete columns reinforced with prefabricated cage system," Journal of Structural Engineering, vol. 134, 2008, pp. 750-757.

[4] LIANG Yangbin, ZENG Zhixing, SU Jianglin, and Chen Yixiong, "Bearing capacity of prefabricated cage system for reinforcing concrete short columns under axial compression," Journal of Huaqiao University (Natural Science), vol. 05, 2014, pp. 576-580.

[5] Ministry of Housing and Urban-Rural Development of the People's Republic of China, GB50010-2010 Code for Design of Concrete Structures. Beijing: China Building Industry Press, 2010, pp. 207-211.

[6] Ministry of Housing and Urban-Rural Development of the People's Republic of China, GB50011-2010 Design Criteria for Seismicresistance of Buildings. Beijing: China Building Industry Press, 2010: pp. 48-71.

[7] ZHAO Liang, "An example of static elastic-plastic analysis based on Midas-Building," Sichuan Building Materials, vol. 04, 2015, pp. 27$28+31$

[8] WANG Yanyan and MO Haihong, "Static elastic-plastic analysis of a super-high-rise building based on MIDAS-Building," Sichuan Building Science, vol. 06, 2012, pp. 181-185.

[9] SUN Wenlin, Studies on Performance-Based Seismic Response Analysis Method for the Steel Frame Structure. Changsha: Hunan University, 2006.

[10] MO Ying, The Analysis of Pile-Soil-Structure Dynamical Interaction Based on Plastic Hinge Theory. Changsha: Hunan University, 2008.

[11] REN Jingyuan, The Study of Earthquake Damage Prediction of Reinforced Concrete Frame-structure. Wuhan: Huazhong University of Science and Technology, 2010. 
[12] JIANG Rui, "Application of SAP2000n in nonlinear static analysis," Journal of Zhengzhou University (Engineering Science), vol. 04, 2004, pp. $20-23+28$.
[13] YANG Nianxiang, Research on the Theory and Methods of Performance Based Seismic Design for Reinforced Concrete Frame Structures. Beijing: Beijing Jiaotong University, 2012. 